\title{
Optimization of SWAN Wave Model to Improve the Accuracy of Winter Storm Wave Prediction in the East Sea
}

\author{
Bongkyo Son ${ }^{1}$ and Kideok Do ${ }^{2}$ \\ ${ }^{1}$ Master's Course, Department of Convergence Study on the Ocean Science and Technology, \\ Korea Maritime \& Ocean University, Busan, Korea \\ ${ }^{2}$ Associate Professor, Department of Ocean Engineering, Korea Maritime \& Ocean University, Busan, Korea
}

KEY WORDS: East Sea, SWAN, ST6, Model skill assessment, Wind waves

\begin{abstract}
In recent years, as human casualties and property damage caused by hazardous waves have increased in the East Sea, precise wave prediction skills have become necessary. In this study, the Simulating WAves Nearshore (SWAN) third-generation numerical wave model was calibrated and optimized to enhance the accuracy of winter storm wave prediction in the East Sea. We used Source Term 6 (ST6) and physical observations from a large-scale experiment conducted in Australia and compared its results to Komen's formula, a default in SWAN. As input wind data, we used Korean Meteorological Agency's (KMA's) operational meteorological model called Regional Data Assimilation and Prediction System (RDAPS), the European Centre for Medium Range Weather Forecasts' newest 5th generation re-analysis data (ERA5), and Japanese Meteorological Agency's (JMA's) meso-scale forecasting data. We analyzed the accuracy of each model's results by comparing them to observation data. For quantitative analysis and assessment, the observed wave data for 6 locations from KMA and Korea Hydrographic and Oceanographic Agency (KHOA) were used, and statistical analysis was conducted to assess model accuracy. As a result, ST6 models had a smaller root mean square error and higher correlation coefficient than the default model in significant wave height prediction. However, for peak wave period simulation, the results were incoherent among each model and location. In simulations with different wind data, the simulation using ERA5 for input wind datashowed the most accurate results overall but underestimated the wave height in predicting high wave events compared to the simulation using RDAPS and JMA meso-scale model. In addition, it showed that the spatial resolution of wind plays a more significant role in predicting high wave events. Nevertheless, the numerical model optimized in this study highlighted some limitations in predicting high waves that rise rapidly in time caused by meteorological events. This suggests that further research is necessary to enhance the accuracy of wave prediction in various climate conditions, such as extreme weather.
\end{abstract}

\section{Introduction}

Ocean wave predictions are made using numerical wave models that calculate the spectrum changes caused by the growth and dissipation of wave energy, mainly using spatial-temporal wind data as input. Numerical wave models can be divided into first-generation, second-generation, and third-generation models according to the number of source terms in their governing equations. Studies on predicting or simulating waves have mainly used third-generation numerical wave models, such as Simulating Waves Nearshore (SWAN), Wave Watch III, and Wave Model (WAM), which solve an action density balance equation to calculate the wave spectrum. Previous studies have developed more accurate simulations of parameters, such as significant wave height and peak period, and have improved modeling performance. Regarding studies on wave prediction in the waters around Korea, Kang et al. (2015) and Eum et al. (2016) employed the SWAN third-generation numerical wave model to simulate waves in the waters around the Korean peninsula using weather forecasting data provided by the European Centre for Medium Range Weather Forecasts (EMCWF) and Japanese Meteorological Agency (JMA) as input data.

Lee et al. (2010) used SWAN to simulate storm waves occurring on the east coast of Korea during winter, and Chun et al. (2014) developed a modified version of WAM for use in shallow waters and simulate storm waves occurring on the east coast. Do and Kim (2018) and Caires et al. (2018) simulated large-height swell-like waves on the east coast of Korea during winter using SWAN and the energy dissipation term coefficient calibration method for white-capping proposed by

Received 20 April 2021, revised 15 June 2021, accepted 2 July 2021

Corresponding author Kideok Do: +82-51-410-5248, kddo@kmou.ac.kr

(c) 2021, The Korean Society of Ocean Engineers

This is an open access article distributed under the terms of the creative commons attribution non-commercial license (http://creativecommons.org/licenses/by-nc/4.0) which permits unrestricted non-commercial use, distribution, and reproduction in any medium, provided the original work is properly cited. 
Rogers et al. (2003). Large-height swell-like waves occur when strong extratropical cyclones develop in strong winds on the East Sea during winter. As the resulting storm waves approach the coast, they develop into waves with a long period (approximately 9-15 seconds) and large height ( $3 \mathrm{~m}$ or more) (Oh et al., 2010). The wind input data used for this include the spatial-temporal wind data from Weather Research and Forecasting (WRF) the ocean weather forecast system's model (Park et al., 2015), Regional Data-Assimilation, and Prediction System (RDAPS) and Local Data-Assimilation and Prediction System (LDAPS) forecast models used for operational meteorological forecasting by Korean Meteorological Agency (KMA). Lee and Ahn (2018) simulated waves in the Yellow Sea and East China Sea using SWAN's energy dissipation term coefficient calibration method for white-capping. Also, KMA is currently operating a wave forecast system (global, regional, and local coastal model), which was built based on Wave Watch III.

Recently, hazardous large-height swell-like waves have repeatedly struck the east coast of Korea in winter (October-February) and have caused many instances of human and property damage. Since 2005, the number of diseased and missing persons due to large-height swell-like waves has reached 70, and the scale of property damage has exceeded an annual average of 10 billion KRW (Lee et al., 2014; Oh et al., 2010). To improve the forecast accuracy for hazardous waves that occur on the east coast of Korea during winter, this study performed numerical simulation of waves using SWAN, a third-generation numerical wave model that is used worldwide, and the Source Term 6 (ST6) developed by Rogers et al. (2012) by calculating physical coefficients based on recent field observations. The results of this study were compared to results obtained using the existing empirical formula created by Komen et al. (1984). As the input wind data for the numerical wave model, this study used data from RDAPS, which is KMA's operational meteorological model, ECMWF's latest 5th generation re-analysis model (ERA5), and the JMA meso-scale model (JMA-MSM). RDAPS data can be downloaded in real-time through KMA's Open MET Data Portal (http://data.kma.go.kr), and the JMA-MSM data were procured from JMA's database. The ERA5 data were obtained using Python and the application programming interface provided by ECMWF. In this study, the operational meteorological model's results and wind data generated as re-analysis data were used as input to the SWAN to simulate the waves that occurred on the East Sea from November 2016 to February 2017. The model results were compared with wave observation data from 6 locations on the open seas operated by KMA and the Korea Hydrographic and Oceanographic Agency (KHOA), and an optimization study was performed to improve the accuracy of the numerical model through error analysis.

\section{Numerical Model}

\subsection{Simulating Waves Nearshore (SWAN)}

This study performed numerical simulation of wave on the East Sea during the winter from November 2016 to February 2017 using SWAN (Booij et al., 1999), a numerical wave model developed at Delft University of Technology in the Netherlands. With its numerical models, SWAN is capable of considering the wave propagation from wind-induced wave growth, refraction, shoaling, reflection, and diffraction. Simultaneously, it can also consider deformation caused by nonlinear wave actions (triad/quadruplet wave-wave interactions) as well as the wave energy dissipation caused by white-capping, breaking, and bottom friction. SWAN's governing equation is a wave action balance equation that expresses waves in the form of a directional wave spectrum and calculates energy spectrum changes in a 2D horizontal space as follows:

$$
\frac{\partial N}{\partial t}+\frac{\partial c_{x} N}{\partial x}+\frac{\partial c_{y} N}{\partial y}+\frac{\partial c_{\sigma} N}{\partial \sigma}+\frac{\partial c_{\theta} N}{\partial \theta}=\frac{S_{T}}{\sigma}
$$

where $\theta$ is the direction, and $\sigma$ represents each frequency, expressed as $2 \pi / f . N$ is the wave action density spectrum, where the wave energy spectrum is divided by each frequency and is expressed as $N=E(\sigma, \theta) / \sigma . c_{x}, c_{y}, c_{\theta}, c_{\sigma}$ are the wave energy propagation speeds at each phase $(x, y, \theta, \sigma)$. on the right side is a source term that shows the generation and reduction of wave energy density caused by wind, nonlinear wave actions, white-capping, bottom friction, and breaking as follows:

$$
S_{T}=S_{i n}+S_{n l 3}+S_{n l 4}+S_{d s, w}+S_{d s, b}+S_{d s, b r}
$$

$S_{i n}$ is the growth in wave energy caused by the wind. $S_{n l 3}$ and $S_{n l 4}$ are the terms for energy dissipation caused by triad/quadruplet wave-wave interactions, respectively. $S_{d s, w}, S_{d s, b}$, and $S_{d s, b r}$ are the terms for energy dissipation caused by white-capping, bottom friction, and depth-induced wave breaking, respectively. White-capping is a breaking phenomenon caused by wave steepness on the open ocean, and it is difficult to describe with an equation due to its strong nonlinear behavior and turbulence phenomena; as such, it is determined by an empirical equation. In SWAN, the term for energy dissipation caused by white-capping $\left(S_{d s, w}\right)$ is expressed by Hasselmann's (1973) pulse-based model, where the wave number $(k)$ becomes a variable, as shown in Eq. (3) (WAMDI Group, 1988):

$$
S_{d s}(\sigma, \theta)=-\tilde{\Gamma \sigma} \frac{k}{\tilde{k}} E(\sigma, \theta)
$$

where $\tilde{\sigma}$ and $\tilde{k}$ are the mean of each frequency and mean wave number, respectively, and $\Gamma$ is the coefficient resulting from the total wave steepness, as shown in Eq. (4):

$$
\Gamma=\Gamma_{K J}=C_{d s}\left((1-\delta)+\delta \frac{k}{\tilde{k}}\right)\left(\frac{\tilde{s}}{\tilde{s}_{P M}}\right)^{p}
$$

where $C_{d s}$ is the energy dissipation coefficient, $\delta$ is the white-capping 
weight value with respect to the wave number, $\tilde{s}$ is the total wave steepness, $\tilde{s}_{P M}$ is the total wave steepness of the Pierson-Moskowitz spectrum, which is $\sqrt{3.02 \times 10^{-3}}$, and $p$ is the exponent of the value of $\tilde{s}$ normalized by $\tilde{s}_{P M}$. In SWAN, the $C_{d s}, \delta$, and $p$ terms are tunable coefficients, and $C_{d s}=2.36 \times 10^{-5}, \delta=0$ and $p=4$ were used as default values. When these values were used, there was a problem with underestimating the wave periods by approximately $10-20 \%$. To improve on this, Rogers et al. (2003) modified $\delta$ from 0 to 1 . Do and Kim (2018) used this to successfully simulate the large-height swell-like waves that occurred on the east coast of Korea in the winter of 2015. Since SWAN version 40.91A, $C_{d s}=2.36 \times 10^{-5}, \delta=1$, and $p=2$ have been used as default values. ST6's term for energy dissipation caused by white-capping is expressed as two phases, as shown in Eq. (5):

$$
\begin{aligned}
& S_{d s}(f, \theta)=\left[T_{1}(f, \theta)+T_{2}(f, \theta)\right] N(f, \theta) \\
& T_{1}(f, \theta)=a_{1} A(f) f\left[\frac{\Delta(f)}{\tilde{E}(f)}\right]^{L} E(f, \theta) \\
& T_{2}(f, \theta)=a_{2}\left[\int_{0}^{k} A\left(f^{\prime}\right)\left[\frac{\Delta\left(f^{\prime}\right)}{\tilde{E}\left(f^{\prime}\right)}\right]^{M} d f^{\prime}\right] E(f, \theta)
\end{aligned}
$$

where $T_{1}$ is the local dissipation term, and $T_{2}$ is the cumulative dissipation term, as given by Eqs. (6) and (7), respectively. This study's numerical wave model used a combination of 4 parameters (DL1M1, UL1M4, UL2M2, and UL4M4) that were verified by Rogers et al. (2012) through white-capping energy dissipation term coefficient calibration. The quantitative values for these parameters are listed in Table 1, where $\tilde{E}(f)$ is the total density spectrum, $L$ and $M$ are the exponents that modify energy dissipation, and $a_{1}$ and $a_{2}$ are constants that adjust the local and cumulative dissipation terms, respectively.

Table 1 ST6 parameters (Rogers et al., 2012)

\begin{tabular}{cccccc}
\hline Parameter & $\tilde{E}(f)$ & $L$ & $M$ & $a_{1}$ & $a_{2}$ \\
\hline DL1M1 & $E(f)$ & 1 & 1 & $2.0 \times 10^{-4}$ & $1.6 \times 10^{-3}$ \\
UL1M4 & $E_{T}(f)$ & 2 & 2 & $8.8 \times 10^{-6}$ & $1.1 \times 10^{-4}$ \\
UL2M2 & $E_{T}(f)$ & 1 & 4 & $5.7 \times 10^{-5}$ & $3.2 \times 10^{-6}$ \\
UL4M4 & $E_{T}(f)$ & 4 & 4 & $5.7 \times 10^{-7}$ & $8.0 \times 10^{-6}$ \\
\hline
\end{tabular}

For detailed information on the aforementioned equations and parameters, see Rogers et al. (2012) and Wave Watch III (The WAVEWATCH III Development Group, 2016). These are used in the same manner in SWAN.

\subsection{Sea Surface Wind Data}

Numerical wave models use spatial-temporal sea surface wind data as input. Because data for the entire scope of the ocean are required, the results of numerical weather forecast models are used. As input wind data for its numerical simulation of waves on the East Sea, this study used wind data from RDAPS, which is operated by KMA, JMA-MSM, and ERA5. The ERA-Interim data provided by ECMWF have a temporal resolution of $6 \mathrm{~h}$, which is considered limited for simulating waves that occur during rapidly changing severe weather (Do and Kim, 2018). The ERA5 single-level sea surface wind data, which have a temporal resolution of $1 \mathrm{~h}$, were used for the input conditions of the numerical simulation of waves. RDAPS uses fourdimensional variational data assimilation (4D-Var) and is operated alongside LDAPS. Although LDAPS has a higher spatial-temporal resolution than RDAPS at $1.5 \mathrm{~km}$ and $3 \mathrm{~h}$, it has limitations regarding numerical simulation of waves on the East Sea because its modeling area is limited to the area around the Korean peninsula, and it does not include the entire East Sea. Also, according to Do and Kim (2018), there is no great difference between the wave simulation results obtained by combining the results of LDAPS and RDAPS and the wave simulation results obtained using results of RDAPS alone; therefore, this study used RDAPS. The JMA-MSM (Saito et al., 2006) wind data are the product of a meso-scale weather forecast model operated by JMA and have a high spatial-temporal resolution. As such, these data have been used as input data in previous studies on numerical simulation of waves in the waters around Korea (Kim et al., 2020; Kwon et al., 2020; Yoon et al., 2020). Table 2 lists the spatial-temporal resolution, area, and data provision period for the 3 models used as input wind data in this study. To summarize the characteristics of each set of wind data, the RDAPS data have better spatial resolution than ERA5; however, at $3 \mathrm{~h}$, its temporal resolution is lower than that of ERA5 and JMA-MSM. ERA5 has fairly poor spatial resolution, but it has a temporal resolution of $1 \mathrm{~h}$, which allows for the analysis of rapidly changing weather conditions during severe weather, making it highly useful. JSM-MSM has a higher spatial

Table 2 Input wind data information

\begin{tabular}{cccc}
\hline & RDAPS & ERA5 & JMA-MSM \\
\hline Provided by & KMA & ECMWF & JMA \\
Type & Forecasting data & Re-Analysis data & Forecasting data \\
Analysis period & 2011 -Present & $1979-$ Present & $2004-$ Present \\
Spatial resolution & $12 \mathrm{~km}$ & $31 \mathrm{~km}$ & $5 \mathrm{~km}$ \\
Temporal resolution & 3 Hourly-Data & Hourly-Data & Hourly-Data \\
Area & $12.2^{\circ} \mathrm{N} \sim(12 \mathrm{~km} \times 491)$ & Global & $22.4-47.6{ }^{\circ} \mathrm{N}$ \\
& $101.5^{\circ} \mathrm{E} \sim(12 \mathrm{~km} \times 419)$ & & $120-150{ }^{\circ} \mathrm{E}$ \\
\hline
\end{tabular}




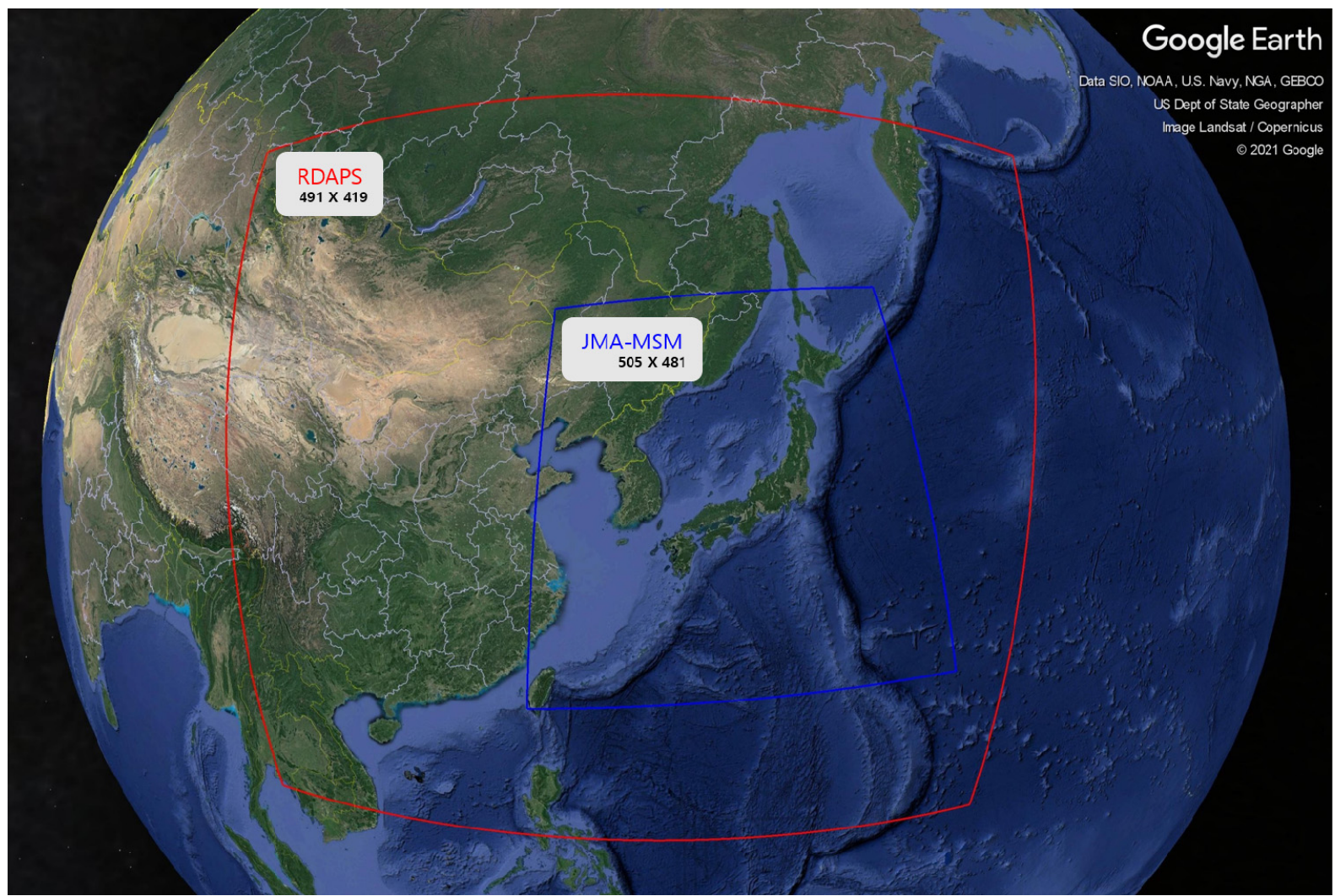

Fig. 1 Domain grids of RDAPS and JMA-MSM

resolution $(5 \mathrm{~km})$ than the other two models, and it has the advantage of providing the same $1 \mathrm{~h}$ temporal resolution as ERA5. Fig. 1 shows the operating range and grid numbers for the RDAPS and JMA-MSM input wind data used in this study. ERA5 is not shown as it is a global model.

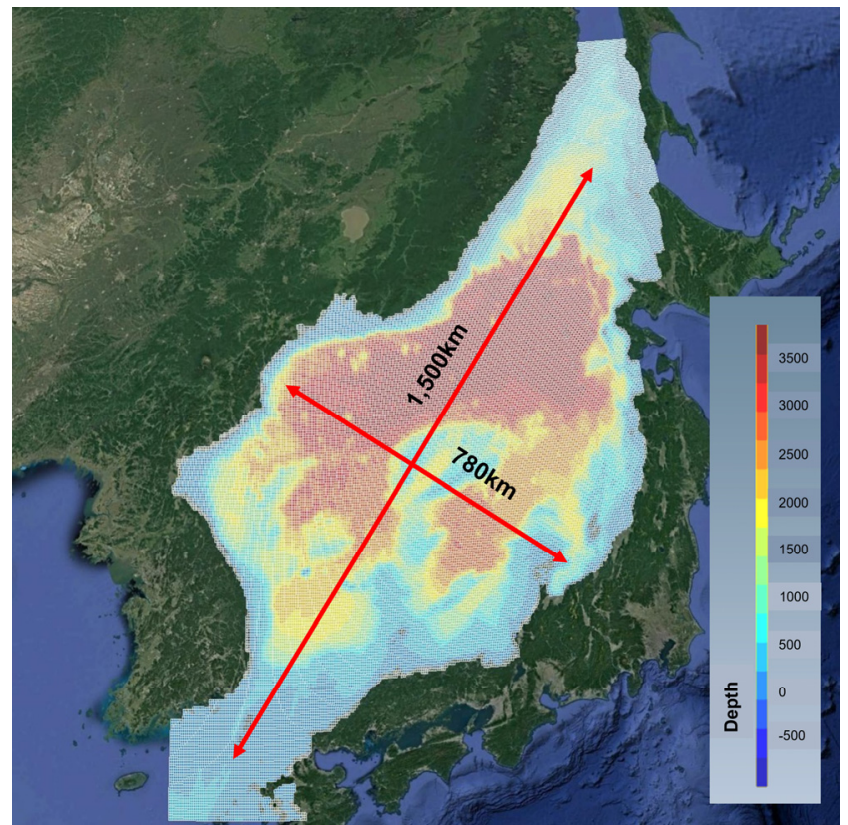

(a) Bottom topography of model computational area (ETOPO1)

\subsection{Physical Coefficients, Grid, and Water Depth}

The calculation area of the model constructed in this study was set as an equidistant grid with a $0.05^{\circ} \times 0.05^{\circ}$ resolution containing the entire East Sea, including the Sea of Okhotsk, to model the development, propagation, and dissipation of storm waves caused by

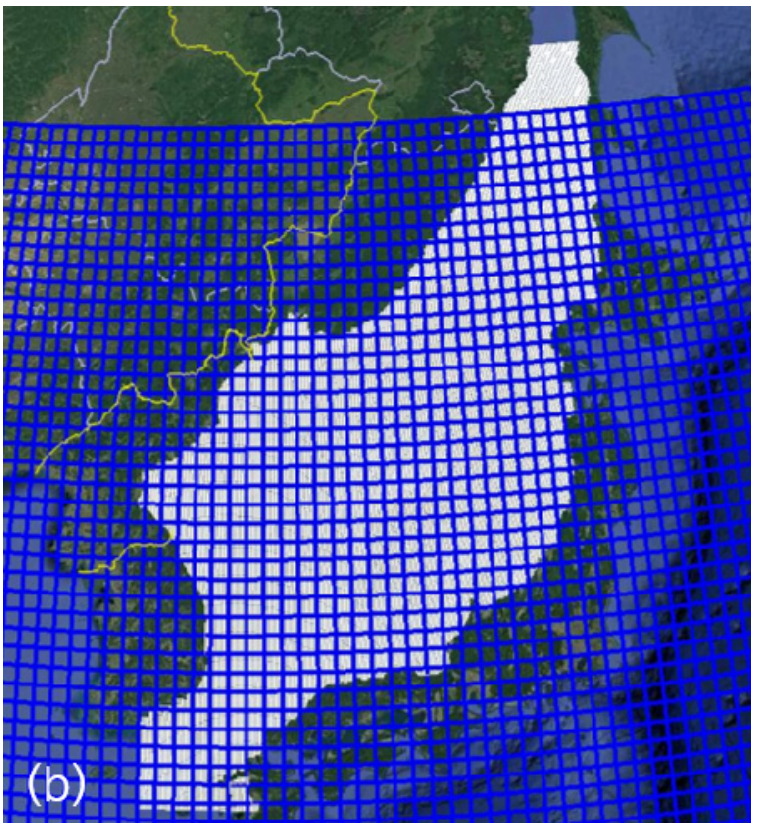

(b) Domain grids of model's computational area (white) and JMA-MSM (blue)

Fig. 2 Computational domains of East Sea wave numerical modeling 
Table 3 Physical parameter settings of SWAN model

\begin{tabular}{cc}
\hline Parameters & Contents \\
\hline Frequency space & 41 bins from 0.03 to $1.5 \mathrm{~Hz}(33-0.67 \mathrm{~s})$ \\
Directional space & 48 bins with $7.5^{\circ}$ intervals $\left(48 \times 7.5^{\circ}=360^{\circ}\right)$ \\
Bottom friction & $0.038 \mathrm{~m}^{2} / \mathrm{s}^{3}$ (Zijlema et al., 2012) \\
Water density & $1,025 \mathrm{~kg} / \mathrm{m}^{3}$ \\
Gravitational acceleration & $9.81 \mathrm{~m} / \mathrm{s}^{2}$ \\
Accuracy & criteria $=99 \%$ (maximum of 99 iterations per time step) \\
Integration time step & 20 min (Fixed) \\
\hline
\end{tabular}

wind. The numerical model's water depths are based on ETOPO1 (https://www.ngdc.noaa.gov/mgg/global/), which are satellite bathymetry data provided by the United States' National Oceanic and Atmosphere Administration (Fig. 2(a)). When the model's grid was generated, the range of the weather data provided by JMA-MSM did not include the northern part of the Sea of Okhotsk, and the model grid for this area was modified as shown in Fig. 2(b).To closely model the periodic components of long-period waves, such as large-height swell-like waves, this study divided the wave energy spectrum frequency into 41 parts from 0.03 to $1.5 \mathrm{~Hz}$ and divided the wave direction into 48 parts in $7.5^{\circ}$ intervals to calculate the wave energy spectrum. Also, the additional physical parameters required to operate the SWAN model were set as listed in Table 3 .

\section{Numerical Wave Model Scenarios and Model Parameters}

This study analyzed wave observation data with a focus on the winter season, in which large-height swell-like waves occur with great frequency. The numerical simulation period was set as November 2016 to February 2017, a period when a large number of large-height swell-like waves occurred.

For the numerical simulation of waves method, the ST6 proposed by Rogers et al. (2012) was applied to the East Sea numerical wave model. For the parameters in the model, combinations of the 4 parameters listed in Table 1 were used to simulate large-height swell-like waves, and these were compared with observation data for validation. Also, research was performed on optimizing the numerical wave model by comparing its results with the results of a simulation that uses an empirical equation by Komen et al. (1984), which is currently the default setting for SWAN. In this study, the model results were divided according to the parameter settings and the input wind data provided by each different organization (RDAPS, ERA5, and JMA-MSM). Table 4 gives an overview of the names, input wind data, model settings, and parameters of the simulation scenarios considered in this study.

As the wave observation data for validating and optimizing the numerical model, this study used data from the KHOA's ocean observation buoys (Northeast of Ulleungdo, E01; Northwest of Ulleungdo, E02) and KMA's open sea buoys (East Sea, DH; Ulleungdo, URD; Pohang, PH; Uljin, UJ), and Fig. 3 shows the locations and water depths of each observation buoy. In this study, the significant wave height and peak wave period data observed at each location were used to analyze the accuracy of the numerical wave model. To judge the model accuracy in detail, this study used wave observation data that had undergone primary data quality validation by Wave Information Network of Korea (Jeong et al., 2018).

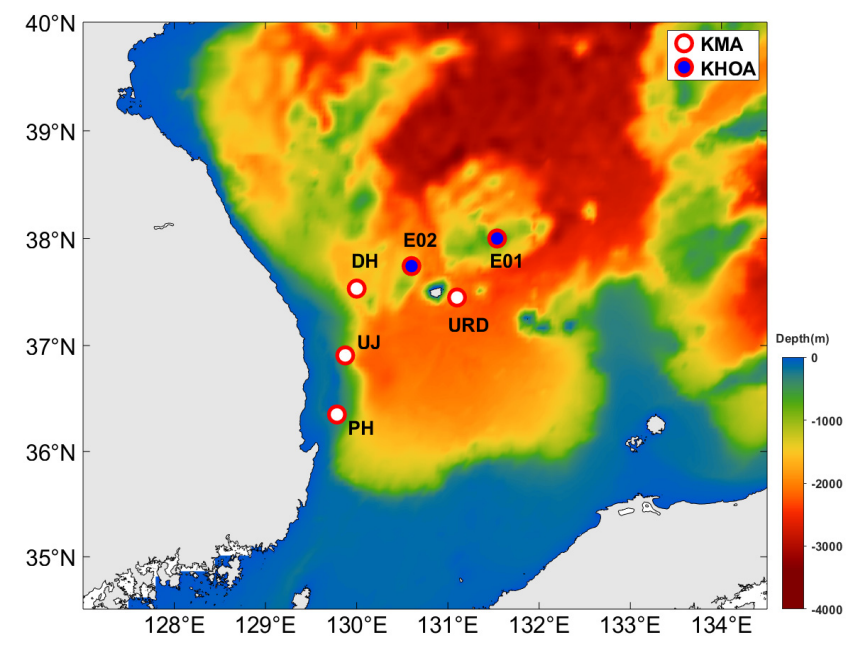

Fig. 3 Locations of wave and wind observation sites from KMA \& KHOA

Table 4 Abbreviation of parameter settings of East Sea wave numerical modeling

\begin{tabular}{|c|c|c|c|c|c|}
\hline & Input wind & & RDAPS & ERA5 & JMA-MSM \\
\hline \multirow{5}{*}{ Physics } & \multirow{4}{*}{$\begin{array}{c}\text { ST6 } \\
\text { Rogers et al. (2012) }\end{array}$} & DL1M1 & RDAPS-DL1M1 & ERA5-DL1M1 & JMA-DL1M1 \\
\hline & & UL1M4 & RDAPS-UL1M4 & ERA5-UL1M4 & JMA-UL1M4 \\
\hline & & UL2M2 & RDAPS-UL2M2 & ERA5-UL2M2 & JMA-UL2M2 \\
\hline & & UL4M4 & RDAPS-UL4M4 & ERA5-UL4M4 & JMA-UL4M4 \\
\hline & Komen et al. (1984) & Komen & RDAPS-Komen & ERA5-Komen & JMA-Komen \\
\hline
\end{tabular}




\section{Validation and Analysis of Numerical Model Results}

In this study, the ST6 and parameter settings, which were developed to improve the numerical wave model proposed by Rogers et al. (2012), were used in simulation of winter waves occurring on the East Sea, and the forecast accuracy regarding significant wave height and peak wave period was evaluated. As mentioned previously, data provided from Korea, Japan, and Europe were used to verify the consistency of the model's results according to the spatial-temporal input wind data. The results were compared with the results of simulations that use the empirical equation by Komen et al. (1984), which is the default setting of the SWAN model. In addition, the simulation results using the wind data provided by different organizations were compared to evaluate the simulation results regarding their input wind data. To quantitatively verify the simulation results, a statistical analysis of the difference between the model results and observation data was performed. The model evaluation items used for this analysis included the bias, root mean square error (RMSE), correlation coefficient ( $\rho$ ), and index of agreement (IOA), as given by Eqs. (8)-(11), respectively:

$$
\begin{aligned}
& \text { Bias }=\frac{1}{n} \sum_{i=1}^{n}\left(M_{i}-O_{i}\right) \\
& \text { RMSE }=\sqrt{\frac{1}{n} \sum_{i=1}^{n}\left(M_{i}-O_{i}\right)^{2}} \\
& \rho=\frac{\sum_{i=1}^{n}\left(M_{i}-\bar{M}\right)\left(O_{i}-\bar{O}\right)}{\sqrt{\left(M_{i}-\bar{M}\right)^{2}\left(O_{i}-\bar{O}\right)}} \\
& \mathrm{IOA}=1-\frac{\sum_{i=1}^{n}\left(M_{i}-O_{i}\right)^{2}}{\sum_{i=1}^{n}\left(\left|M_{i}-\bar{O}\right|+\left|O_{i}-\bar{O}\right|\right)^{2}}
\end{aligned}
$$

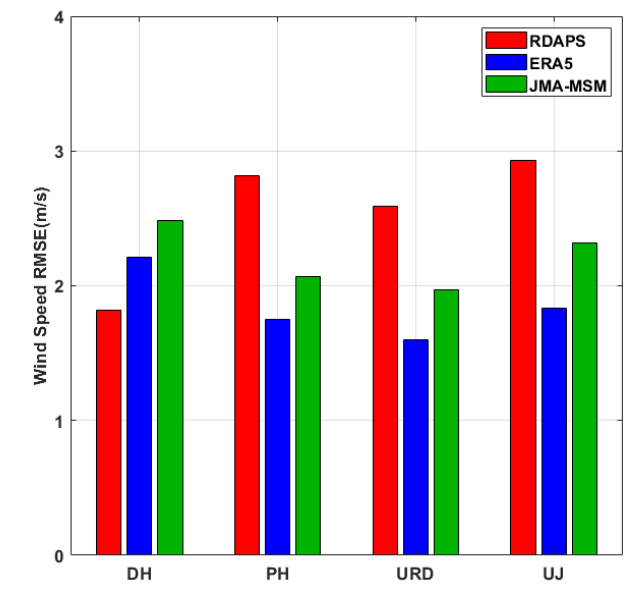

where $n$ is the number of observation data, $M$ is the model's result value, $O$ is the observed value, $\bar{M}$ and $\bar{O}$ are the respective mean values of $M, O$. In the statistical analysis, a comparison was made between the observed values and model results over a $1 \mathrm{~h}$ interval only in cases where the values in the observed significant wave height time series data during the interval were $\geq 1.0 \mathrm{~m}$. This was done to systematically evaluate the actual prediction accuracy by removing the observation data error that occurs when wave height is low.

First, to evaluate the accuracy of the weather forecast data used as input to the numerical wave model, the wind speed and wind direction observed at the locations in Fig. 3 were compared to the input wind data, and the RMSE values for each weather model were plotted in a bar graph (Fig. 4). In the comparison process, the 2017 wind data from the KHOA-operated ocean observation buoys E01 and E02 were missing, and the data from the KMA-operated weather observation buoys DH, PH, URD, and UJ were used. When the data were analyzed, the ERA5 wind speed and wind direction had high overall accuracy, but the RDAPS forecast model had the lowest error at the DH. In the case of wind direction, there was no great difference in accuracy between the wind data produced by JMA-MSM and ERA5. In the case of wind speed, the accuracy of JMA-MSM was found to be excellent considering that it is a forecast model (Fig. 4 shows that JMA-MSM's wind speed had a higher RMSE of approximately $0.5 \mathrm{~m} / \mathrm{s}$ than ERA5, which is re-analysis data.).

To find the input wind data and model composition that are most suitable for simulating large-height swell-like waves on the east coast of Korea in winter, significant wave height results for each simulation scenario were quantitatively analyzed, and the error statistics are listed in Table 5. It can be seen that the significant wave height simulation results from the ST6 configured with the UL4M4 parameter combination had the lowest error (RMSE of $0.02-0.18 \mathrm{~m}$ ) and the highest correlation coefficient and IOA, regardless of the input wind data. In contrast, when the DL1M1 parameter combination was used with the ST6, the simulation accuracy was the lowest. Fig. 5 shows a time series of the observation data and the significant wave height simulation results for each location predicted using the UL4M4

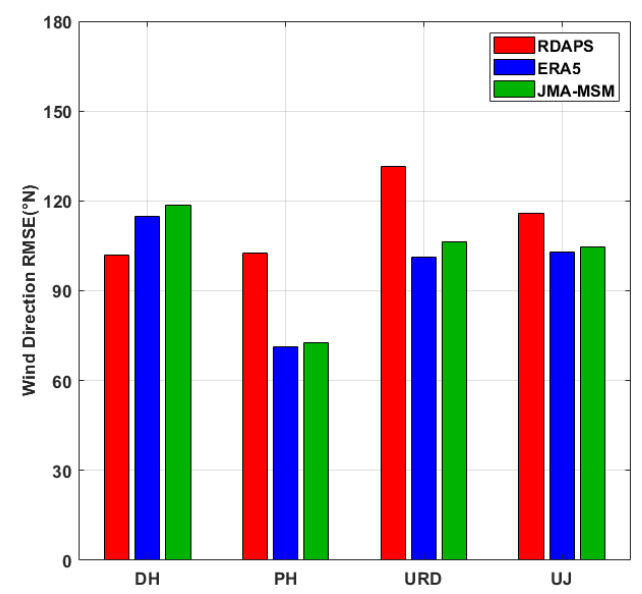

Fig. 4 Bar graphs of RMSE of input wind data (wind speed and direction) at 4 locations 
parameters, which had the highest accuracy of all parameter settings (RDAPS/ERA5/JMA-MSM-UL4M4). To evaluate the forecast accuracy for hazardous waves that occur during severe weather, the ST6's significant wave height simulation results using 4 parameter settings (DL1M1, UL1M4, UL2M2, UL4M4) were divided up according to the input wind data for December 19-31, 2016, which was a period when the significant wave height observed values were 4 $\mathrm{m}$ or greater and the numerical model's error was high, and this is shown in Fig. 6. Here, there was no great difference in the error values between the model and observation data for each of the observation locations; therefore, the E01 and DH were selected as representatives from among the KHOA and KMA observation locations, and their data are shown as time series. It can be seen that there was no great difference between the simulation results that used the 3 parameter combinations UL1M4, UL2M2, and UL4M4, excluding DL1M1.
However, as Table 5 shows, the results using the UL4M4 parameters, which produced the best statistics, had the largest significant wave height estimates, and these results were close to the observed values. In contrast, the results obtained using the DL1M1 parameters, which showed the worst model results in Table 4, estimated the waves to be lower than for other settings. Looking at the significant wave height results for December 23 and 24 at E01 and December 28 at DH in Fig. 6 , the results obtained using the 3 parameter settings UL1M4, UL2M2, and UL4M4 all showed the significant wave heights to be approximately $0.1-0.2 \mathrm{~m}$ higher than when using DL1M1, regardless of the input wind data. However, looking at the results for December 22 , when the observed significant wave height rapidly increased, the wave height estimated by the DL1M1 settings was the largest, contrary to the previous results. It is believed that this is because the DL1M1 parameter combination does not use the ST6, which employs the new

Table 5 Skill assessment of East Sea wave model results for significant wave height

\begin{tabular}{|c|c|c|c|c|c|c|c|c|c|c|c|c|c|c|c|}
\hline \multirow[b]{2}{*}{ Location } & \multirow[b]{2}{*}{$n$} & \multirow[b]{2}{*}{ Mean } & \multirow[b]{2}{*}{ Physics } & \multicolumn{4}{|c|}{ RDAPS } & \multicolumn{4}{|c|}{ ERA5 } & \multicolumn{4}{|c|}{ JMA-MSM } \\
\hline & & & & Bias & RMSE & $\rho$ & IOA & Bias & RMSE & $\rho$ & IOA & Bias & RMSE & $\rho$ & IOA \\
\hline \multirow{5}{*}{ E01 } & \multirow{5}{*}{2314} & \multirow{5}{*}{2.27} & DL1M1 & 0.25 & 0.60 & 0.85 & 0.90 & 0.41 & 0.57 & 0.92 & 0.91 & 0.19 & 0.50 & 0.89 & 0.94 \\
\hline & & & UL1M4 & 0.10 & 0.53 & 0.86 & 0.92 & 0.25 & 0.44 & 0.93 & 0.94 & 0.03 & 0.42 & 0.90 & 0.95 \\
\hline & & & UL2M2 & 0.10 & 0.52 & 0.86 & 0.92 & 0.24 & 0.44 & 0.93 & 0.94 & 0.02 & 0.42 & 0.90 & 0.95 \\
\hline & & & UL4M4 & 0.06 & 0.50 & 0.87 & 0.93 & 0.20 & 0.41 & 0.93 & 0.95 & -0.01 & 0.41 & 0.91 & 0.95 \\
\hline & & & Komen & 0.26 & 0.59 & 0.85 & 0.90 & 0.37 & 0.52 & 0.93 & 0.92 & 0.18 & 0.45 & 0.90 & 0.94 \\
\hline \multirow{5}{*}{ E02 } & \multirow{5}{*}{2246} & \multirow{5}{*}{2.14} & DL1M1 & 0.13 & 0.57 & 0.82 & 0.90 & 0.36 & 0.51 & 0.91 & 0.91 & 0.06 & 0.47 & 0.88 & 0.93 \\
\hline & & & UL1M4 & -0.01 & 0.51 & 0.84 & 0.91 & 0.21 & 0.39 & 0.92 & 0.94 & -0.08 & 0.42 & 0.90 & 0.94 \\
\hline & & & UL2M2 & -0.01 & 0.50 & 0.84 & 0.91 & 0.20 & 0.39 & 0.93 & 0.94 & -0.08 & 0.42 & 0.90 & 0.94 \\
\hline & & & UL4M4 & -0.03 & 0.49 & 0.84 & 0.92 & 0.16 & 0.37 & 0.93 & 0.95 & -0.11 & 0.41 & 0.90 & 0.95 \\
\hline & & & Komen & 0.15 & 0.53 & 0.83 & 0.90 & 0.32 & 0.46 & 0.92 & 0.92 & 0.06 & 0.40 & 0.90 & 0.95 \\
\hline \multirow{5}{*}{ DH } & \multirow{5}{*}{2228} & \multirow{5}{*}{2.06} & DL1M1 & 0.35 & 0.50 & 0.91 & 0.92 & 0.58 & 0.74 & 0.85 & 0.80 & 0.28 & 0.53 & 0.86 & 0.90 \\
\hline & & & UL1M4 & 0.23 & 0.40 & 0.92 & 0.94 & 0.46 & 0.64 & 0.86 & 0.84 & 0.16 & 0.45 & 0.87 & 0.93 \\
\hline & & & UL2M2 & 0.23 & 0.39 & 0.92 & 0.94 & 0.46 & 0.64 & 0.86 & 0.84 & 0.16 & 0.44 & 0.87 & 0.93 \\
\hline & & & UL4M4 & 0.20 & 0.37 & 0.93 & 0.95 & 0.43 & 0.62 & 0.86 & 0.84 & 0.13 & 0.43 & 0.88 & 0.93 \\
\hline & & & Komen & 0.35 & 0.47 & 0.93 & 0.92 & 0.52 & 0.68 & 0.87 & 0.82 & 0.26 & 0.48 & 0.88 & 0.91 \\
\hline \multirow{5}{*}{$\mathrm{PH}$} & \multirow{5}{*}{2112} & \multirow{5}{*}{1.92} & DL1M1 & 0.33 & 0.61 & 0.78 & 0.84 & 0.52 & 0.67 & 0.86 & 0.78 & 0.11 & 0.55 & 0.76 & 0.89 \\
\hline & & & UL1M4 & 0.21 & 0.52 & 0.81 & 0.88 & 0.42 & 0.56 & 0.89 & 0.84 & 0.03 & 0.46 & 0.82 & 0.90 \\
\hline & & & UL2M2 & 0.21 & 0.51 & 0.82 & 0.89 & 0.41 & 0.55 & 0.89 & 0.84 & 0.03 & 0.45 & 0.82 & 0.90 \\
\hline & & & UL4M4 & 0.18 & 0.49 & 0.83 & 0.89 & 0.38 & 0.53 & 0.90 & 0.86 & 0.01 & 0.43 & 0.84 & 0.91 \\
\hline & & & Komen & 0.30 & 0.55 & 0.82 & 0.86 & 0.45 & 0.59 & 0.89 & 0.83 & 0.12 & 0.44 & 0.84 & 0.90 \\
\hline \multirow{5}{*}{ URD } & \multirow{5}{*}{2416} & \multirow{5}{*}{2.17} & DL1M1 & 0.26 & 0.60 & 0.84 & 0.89 & 0.44 & 0.59 & 0.90 & 0.89 & 0.25 & 0.51 & 0.89 & 0.92 \\
\hline & & & UL1M4 & 0.13 & 0.52 & 0.85 & 0.92 & 0.29 & 0.46 & 0.91 & 0.93 & 0.11 & 0.41 & 0.90 & 0.95 \\
\hline & & & UL2M2 & 0.13 & 0.51 & 0.85 & 0.92 & 0.28 & 0.46 & 0.92 & 0.93 & 0.10 & 0.41 & 0.90 & 0.95 \\
\hline & & & UL4M4 & 0.09 & 0.49 & 0.86 & 0.92 & 0.24 & 0.43 & 0.92 & 0.94 & 0.07 & 0.39 & 0.91 & 0.95 \\
\hline & & & Komen & 0.27 & 0.57 & 0.85 & 0.90 & 0.40 & 0.54 & 0.92 & 0.90 & 0.24 & 0.45 & 0.90 & 0.93 \\
\hline \multirow{5}{*}{ UJ } & \multirow{5}{*}{2250} & \multirow{5}{*}{2.01} & DL1M1 & 0.27 & 0.68 & 0.75 & 0.84 & 0.58 & 0.72 & 0.89 & 0.80 & 0.23 & 0.57 & 0.82 & 0.88 \\
\hline & & & UL1M4 & 0.16 & 0.58 & 0.79 & 0.87 & 0.45 & 0.60 & 0.91 & 0.86 & 0.11 & 0.48 & 0.85 & 0.91 \\
\hline & & & UL2M2 & 0.15 & 0.57 & 0.79 & 0.88 & 0.44 & 0.59 & 0.91 & 0.86 & 0.10 & 0.48 & 0.85 & 0.92 \\
\hline & & & UL4M4 & 0.13 & 0.55 & 0.80 & 0.89 & 0.41 & 0.56 & 0.92 & 0.87 & 0.08 & 0.46 & 0.86 & 0.92 \\
\hline & & & Komen & 0.27 & 0.61 & 0.79 & 0.86 & 0.51 & 0.65 & 0.91 & 0.83 & 0.21 & 0.50 & 0.86 & 0.90 \\
\hline
\end{tabular}


E01

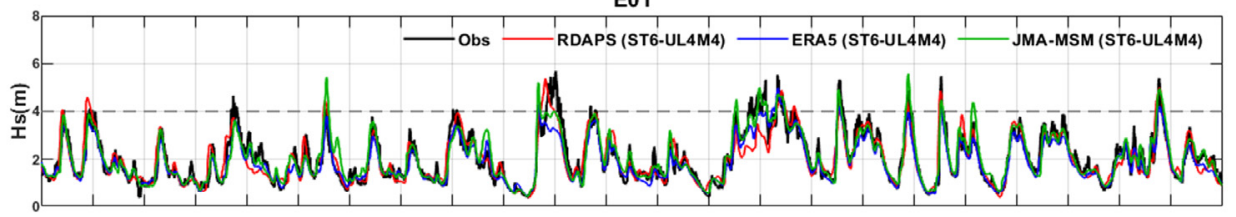

E02

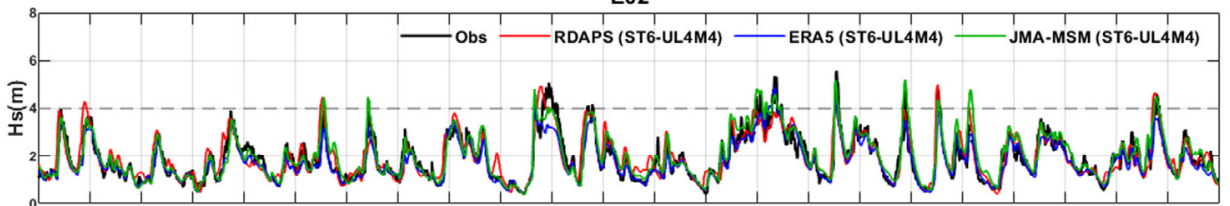

$\mathrm{DH}$

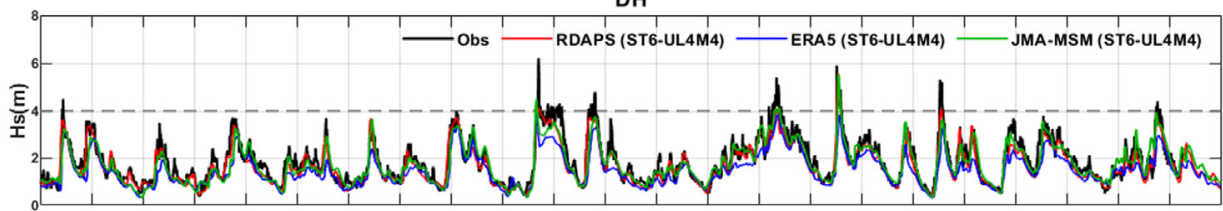

$\mathrm{PH}$

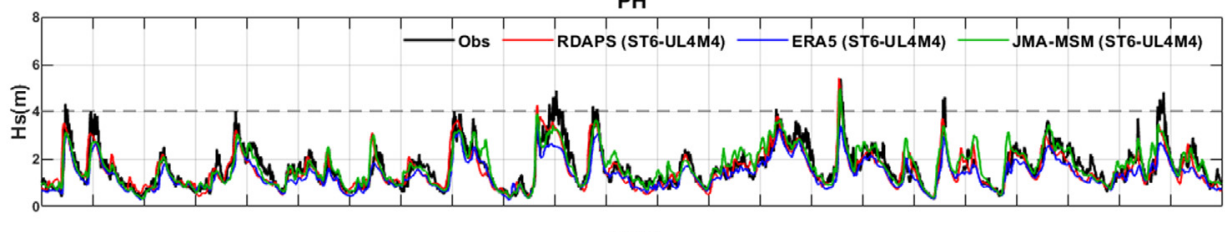

URD

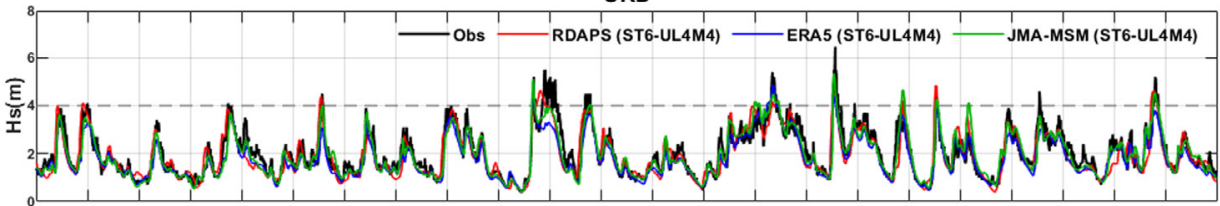

UJ

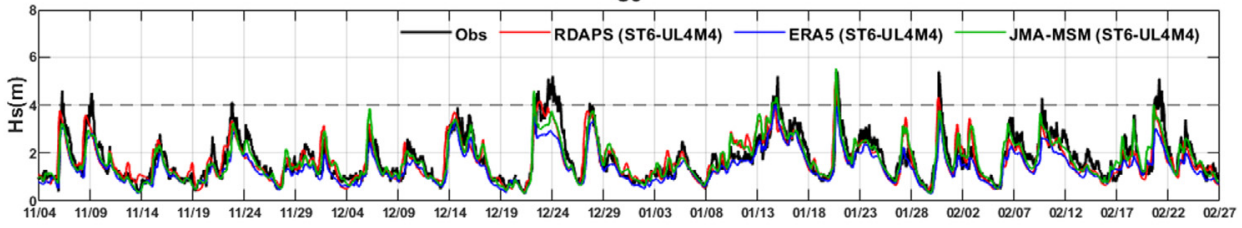

Fig. 5 Time series of observation data and ST6 (UL4M4) simulation results for significant wave height (Hs) using 3 input wind data sources (RDAPS, ERA5, and JMA-MSM) at 6 locations
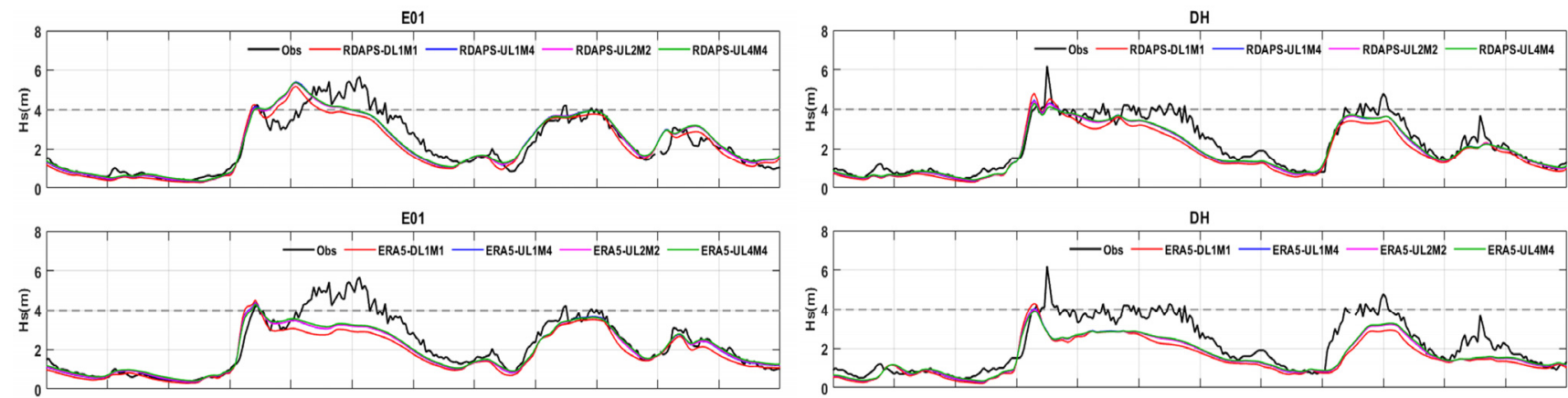

E01
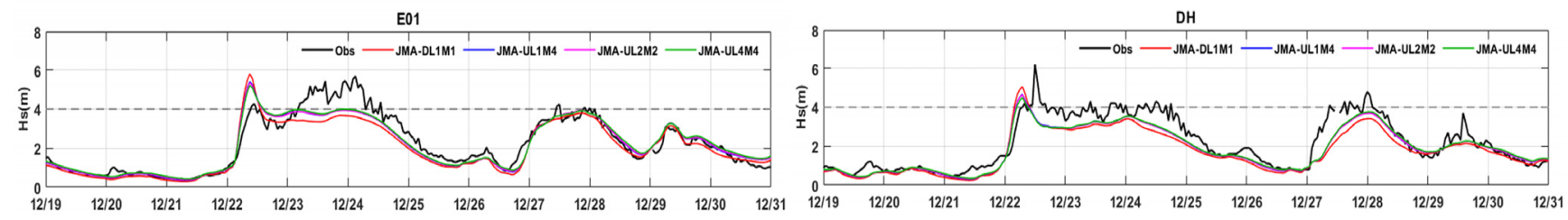

Fig. 6 Time series of observation data and ST6 simulation results for significant wave height (Hs) with 3 input wind data sources at E01 and DH (12.19.2016-12.31.2016) 
value for calculating the coefficient of energy dissipation due to white-capping, and therefore DL1M1 shows somewhat different characteristics in the predicted process of wave development.

To analyze the simulation accuracy regarding wave period, Table 6 lists the statistics for error between the peak wave period results of this study's numerical wave model and the observation data. From the simulation result statistics, it can be seen that there was poor consistency in the statistical comparative analysis results for the four ST6 models (DL1M1, UL1M4, UL2M2, UL4M4) for each combination of input data and observing locations used, and it is difficult to distinguish the model with the best results. All of the peak wave period model results for the KMA observing location UJ had very poor reproducibility, with a correlation coefficient of less than 0.51. Fig. 7 shows the peak wave period simulation results at each observing location for the ST6 models that showed the best reproducibility for significant wave height (RDAPS/ERA5/JMAMSM-UL4M4) along with the observation results in a time series. As can be seen in the figure, the model was not able to simulate the observed peak wave periods at UJ from December 20, 2016 to January 18,2017 . It is believed that an observation error occurred because the peak wave period values observed at UJ at that time were somewhat smaller than at other observing locations, and in the future, it will be necessary to examine the wave data quality management and data analysis methods to identify the cause of the error.

To examine the ST6's wave prediction improvement effect, this study compared ST6's simulation results to simulation results that use the empirical equation by Komen et al. (1984), which is the default setting for the SWAN model. Time series data for December 19 and

Table 6 Skill assessment of East Sea wave model results for peak wave period

\begin{tabular}{|c|c|c|c|c|c|c|c|c|c|c|c|c|c|c|c|}
\hline \multirow[b]{2}{*}{ Location } & \multirow[b]{2}{*}{$n$} & \multirow[b]{2}{*}{ Mean } & \multirow[b]{2}{*}{ Physics } & \multicolumn{4}{|c|}{ RDAPS } & \multicolumn{4}{|c|}{ ERA5 } & \multicolumn{4}{|c|}{ JMA-MSM } \\
\hline & & & & Bias & RMSE & $\rho$ & IOA & Bias & RMSE & $\rho$ & IOA & Bias & RMSE & $\rho$ & IOA \\
\hline \multirow{5}{*}{ E01 } & \multirow{5}{*}{2314} & \multirow{5}{*}{2.27} & DL1M1 & -0.31 & 0.95 & 0.82 & 0.89 & -0.03 & 0.65 & 0.89 & 0.94 & -0.54 & 0.96 & 0.86 & 0.89 \\
\hline & & & UL1M4 & -0.42 & 0.97 & 0.82 & 0.88 & -0.20 & 0.67 & 0.90 & 0.94 & -0.67 & 1.02 & 0.87 & 0.88 \\
\hline & & & UL2M2 & -0.38 & 0.95 & 0.82 & 0.89 & -0.18 & 0.67 & 0.90 & 0.94 & -0.64 & 1.00 & 0.87 & 0.88 \\
\hline & & & UL4M4 & -0.40 & 0.94 & 0.83 & 0.89 & -0.22 & 0.68 & 0.90 & 0.94 & -0.67 & 1.01 & 0.87 & 0.88 \\
\hline & & & Komen & -0.45 & 0.97 & 0.83 & 0.88 & -0.28 & 0.69 & 0.90 & 0.94 & -0.73 & 1.06 & 0.87 & 0.87 \\
\hline \multirow{5}{*}{ E02 } & \multirow{5}{*}{2246} & \multirow{5}{*}{2.14} & DL1M1 & -0.46 & 1.00 & 0.82 & 0.88 & -0.22 & 0.72 & 0.89 & 0.93 & -0.69 & 1.08 & 0.86 & 0.87 \\
\hline & & & UL1M4 & -0.56 & 1.04 & 0.83 & 0.86 & -0.39 & 0.78 & 0.89 & 0.92 & -0.82 & 1.14 & 0.87 & 0.86 \\
\hline & & & UL2M2 & -0.53 & 1.02 & 0.83 & 0.87 & -0.36 & 0.77 & 0.88 & 0.92 & -0.79 & 1.12 & 0.87 & 0.86 \\
\hline & & & UL4M4 & -0.55 & 1.01 & 0.83 & 0.87 & -0.40 & 0.79 & 0.89 & 0.92 & -0.82 & 1.13 & 0.87 & 0.86 \\
\hline & & & Komen & -0.59 & 1.08 & 0.82 & 0.86 & -0.46 & 0.83 & 0.89 & 0.91 & -0.87 & 1.18 & 0.87 & 0.85 \\
\hline \multirow{5}{*}{ DH } & \multirow{5}{*}{2228} & \multirow{5}{*}{2.06} & DL1M1 & -0.09 & 1.10 & 0.79 & 0.88 & 0.20 & 1.31 & 0.72 & 0.84 & -0.27 & 1.30 & 0.73 & 0.85 \\
\hline & & & UL1M4 & -0.22 & 1.09 & 0.80 & 0.89 & 0.01 & 1.24 & 0.74 & 0.86 & -0.44 & 1.31 & 0.74 & 0.85 \\
\hline & & & UL2M2 & -0.20 & 1.08 & 0.80 & 0.89 & 0.02 & 1.23 & 0.75 & 0.86 & -0.42 & 1.30 & 0.74 & 0.85 \\
\hline & & & UL4M4 & -0.22 & 1.07 & 0.81 & 0.89 & -0.02 & 1.22 & 0.75 & 0.86 & -0.44 & 1.30 & 0.75 & 0.85 \\
\hline & & & Komen & -0.24 & 1.13 & 0.79 & 0.88 & -0.03 & 1.26 & 0.75 & 0.86 & -0.47 & 1.33 & 0.75 & 0.85 \\
\hline \multirow{5}{*}{$\mathrm{PH}$} & \multirow{5}{*}{2112} & \multirow{5}{*}{1.92} & DL1M1 & -0.13 & 1.45 & 0.68 & 0.81 & 0.21 & 1.24 & 0.78 & 0.88 & -0.08 & 1.37 & 0.74 & 0.86 \\
\hline & & & UL1M4 & -0.26 & 1.44 & 0.68 & 0.82 & -0.03 & 1.23 & 0.78 & 0.88 & -0.33 & 1.32 & 0.76 & 0.86 \\
\hline & & & UL2M2 & -0.24 & 1.43 & 0.69 & 0.82 & -0.02 & 1.22 & 0.78 & 0.88 & -0.29 & 1.33 & 0.76 & 0.86 \\
\hline & & & UL4M4 & -0.27 & 1.43 & 0.69 & 0.82 & -0.06 & 1.23 & 0.77 & 0.87 & -0.36 & 1.34 & 0.75 & 0.86 \\
\hline & & & Komen & -0.31 & 1.50 & 0.67 & 0.81 & -0.07 & 1.24 & 0.78 & 0.88 & -0.34 & 1.42 & 0.73 & 0.85 \\
\hline \multirow{5}{*}{ URD } & \multirow{5}{*}{2416} & \multirow{5}{*}{2.17} & DL1M1 & 0.05 & 1.20 & 0.72 & 0.85 & 0.32 & 1.00 & 0.81 & 0.89 & -0.18 & 1.11 & 0.77 & 0.87 \\
\hline & & & UL1M4 & -0.06 & 1.17 & 0.73 & 0.86 & 0.15 & 0.95 & 0.82 & 0.90 & -0.33 & 1.12 & 0.78 & 0.87 \\
\hline & & & UL2M2 & -0.03 & 1.16 & 0.73 & 0.86 & 0.18 & 0.96 & 0.82 & 0.90 & -0.29 & 1.11 & 0.78 & 0.87 \\
\hline & & & UL4M4 & -0.05 & 1.15 & 0.74 & 0.86 & 0.14 & 0.94 & 0.82 & 0.90 & -0.32 & 1.11 & 0.78 & 0.87 \\
\hline & & & Komen & -0.10 & 1.18 & 0.73 & 0.85 & 0.06 & 0.93 & 0.83 & 0.90 & -0.39 & 1.13 & 0.79 & 0.88 \\
\hline \multirow{5}{*}{$\mathrm{UJ}$} & \multirow{5}{*}{2250} & \multirow{5}{*}{2.01} & DL1M1 & -0.72 & 2.23 & 0.36 & 0.61 & -0.59 & 1.95 & 0.50 & 0.69 & -0.98 & 2.24 & 0.42 & 0.64 \\
\hline & & & UL1M4 & -0.85 & 2.25 & 0.37 & 0.61 & -0.76 & 2.02 & 0.49 & 0.68 & -1.11 & 2.29 & 0.43 & 0.63 \\
\hline & & & UL2M2 & -0.83 & 2.24 & 0.37 & 0.61 & -0.74 & 2.00 & 0.49 & 0.68 & -1.09 & 2.28 & 0.43 & 0.63 \\
\hline & & & UL4M4 & -0.86 & 2.23 & 0.38 & 0.61 & -0.79 & 2.03 & 0.49 & 0.67 & -1.12 & 2.29 & 0.43 & 0.63 \\
\hline & & & Komen & -0.87 & 2.26 & 0.38 & 0.61 & -0.85 & 2.05 & 0.51 & 0.69 & -1.16 & 2.30 & 0.45 & 0.64 \\
\hline
\end{tabular}


E01

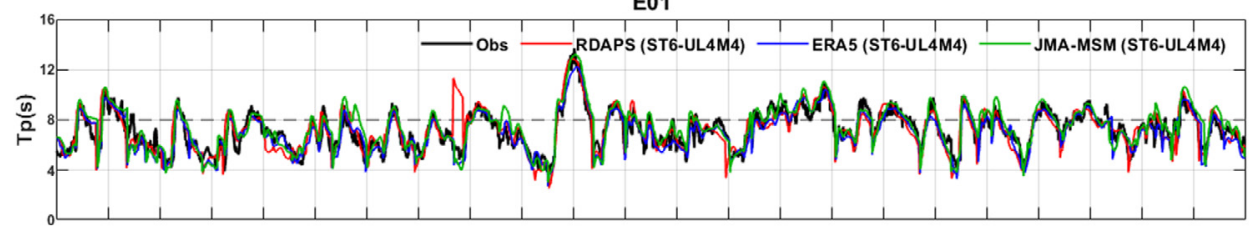

E02

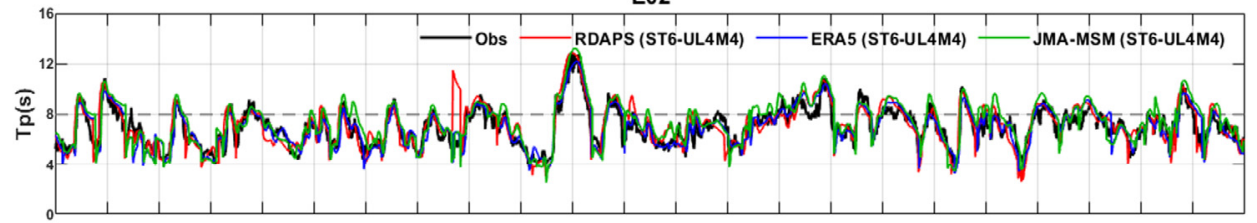

DH

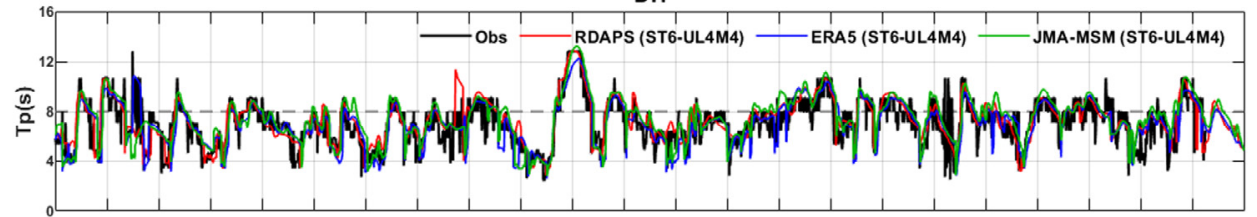

$\mathrm{PH}$

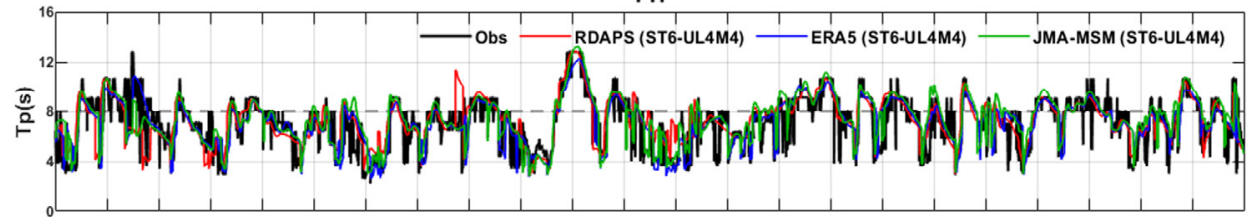

URD

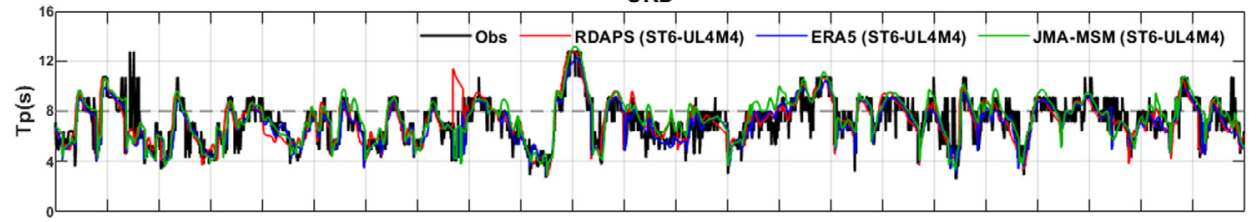

UJ

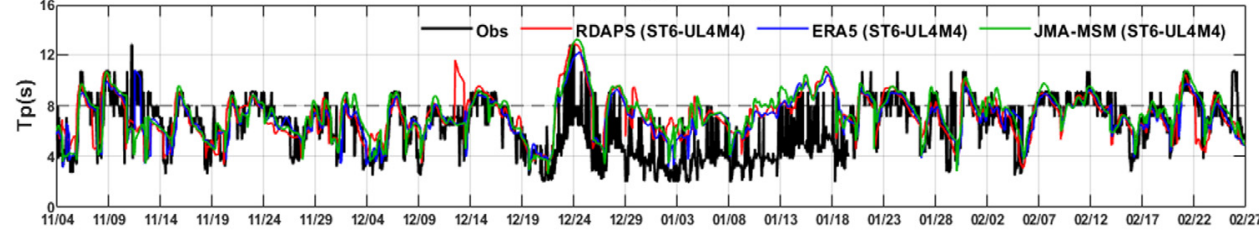

Fig. 7 Time series of observation data and ST6 (UL4M4) simulation results for peak wave period ( Tp) using 3 input wind data sources (RDAPS, ERA5, and JMA-MSM) at 6 locations

31, 2016 at E01 and DH are shown in Fig. 8. It can be seen that the two simulation results show no great difference in terms of peak wave period; however, in the case of significant wave height, ST6 predicted the wave height to be somewhat higher overall compared to the results obtained using the empirical equation by Komen et al. (1984). The difference between the two methods' results is clear between December 22 and 24, when a large significant wave height occurred and temporal variability was high. Looking at the statistical analysis values listed in Table 4, it can be seen that RDAPS/ERA5/ JMA-UL4M4 had an RSME that was lower by a maximum of $0.1 \mathrm{~m}$ and a lower deviation than RDAPS/ERA5/JMA-Komen, and the IOA and correlation coefficient were the same, or slightly higher for UL4M4. Thus, the simulation results using the empirical equation by Komen et al. (1984) were more accurate than the results of the ST6 using the DL1M1 setting; still, they were less accurate than when using the other settings, i.e., UL1M4, UL2M2, and UL4M4. This shows that, depending on the settings, the ST6 can predict significant wave height more accurately than the empirical equation by Komen et al. (1984). However, this study targeted only some periods when swell-like waves occurred. As such, it will be necessary to examine the numerical wave model's suitability for waves that occur in various weather conditions (large-height swell-like waves, storm waves, etc.), and it is believed that the wave prediction accuracy can be improved further by providing optimal parameters based on such an examination.

This study used various numerical simulation scenarios to find that the ST6's UL4M4 parameter setting had the highest reproducibility for large-height swell-like waves that occur on the East Sea. Ultimately, this study evaluated the accuracy of numerical wave models according to the input wind data provided different organizations. Fig. 9 shows 

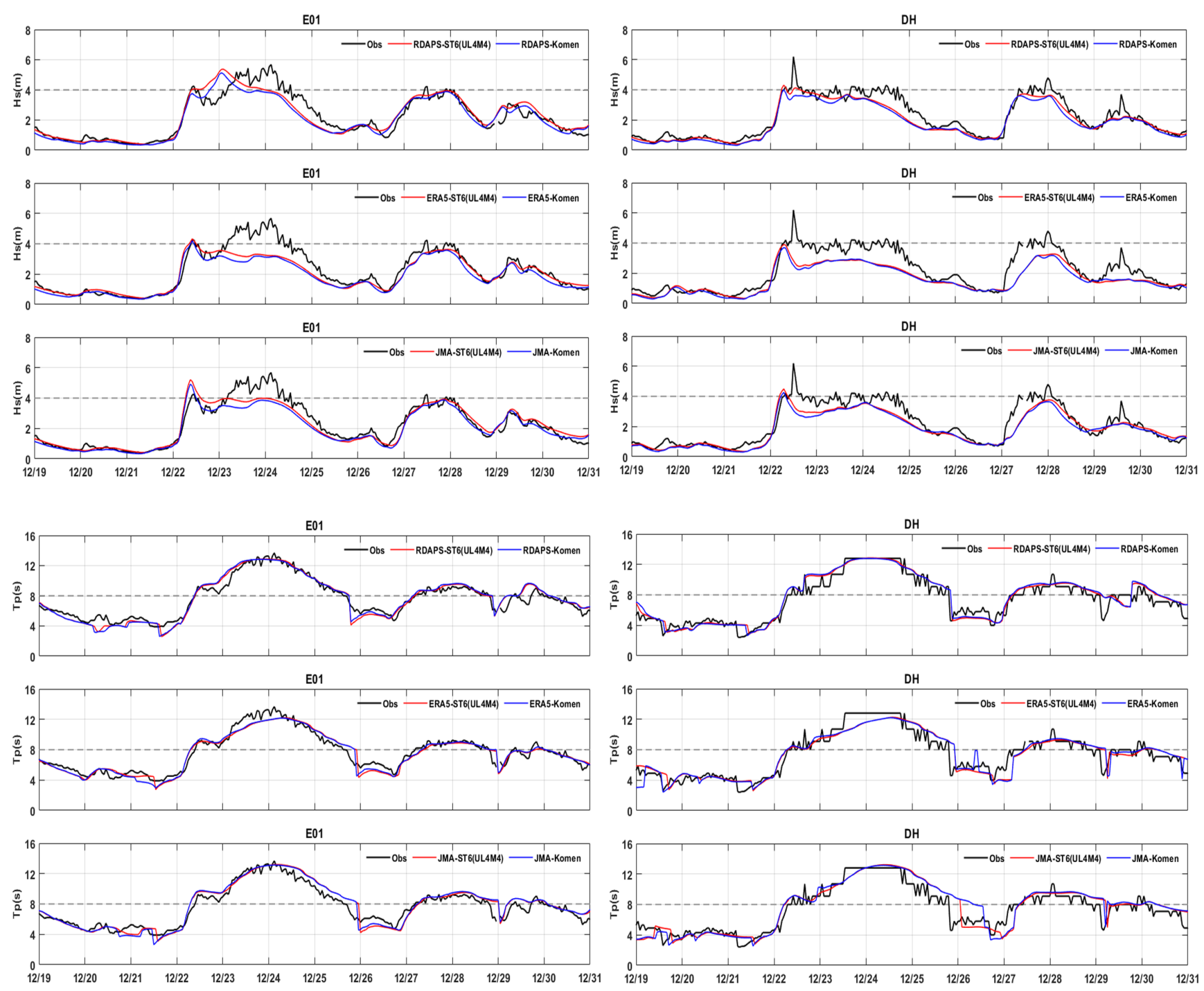

Fig. 8 Time series of observation data, ST6 (UL4M4) simulation results, and Komen et al. (1984) formula-based model prediction for significant wave height $(H s)$ and peak wave period $(T p)$ at E01 and DH (12.19.2016-12.31.2016)

bar graphs of the RMSEs and correlation coefficients of the significant wave height and peak wave period simulation results of the model with UL4M4 settings using the wind data provided by RDAPS, ERA5, and JMA-MSM. These graphs examine the accuracy of the numerical simulation of waves according to the input wind data. It can be seen that the simulation results for significant wave height using the ERA5 wind data as input had the highest correlation coefficient, except in the case of the location DH. This is because the ERA5 wind data were created through later re-analysis, unlike the other wind data, which shows that the accuracy of the input wind data plays an important role in the simulation of significant wave height. However, the ERA5 simulation results had a higher RMSE than the simulation results from JMA-MSM at all other locations except for E01 and E02, and they had a higher RMSE than the simulation results from RDAPS at the DH, $\mathrm{PH}$, and UJ. It can be said that when the ERA5 wind data were used as the input wind data, the overall significant wave height reproducibility was excellent, but accuracy was poor when simulating large-height waves with great temporal variability. This can be seen in Fig. 6, which shows Fig. 5's simulation results in detail around both February 22 and December 24 at E01 and DH. The wind data provided by the ERA5 model are based on a global model, and while their temporal resolution is excellent compared to the RDAPS and JMA-MSM data, their spatial resolution is poor. Therefore, it is believed that the spatial resolution of the input wind data plays an important role in simulating hazardous large-height waves that rapidly increase and change during severe weather. Looking at the simulation results for peak wave period, except at the UJ, which had a correlation coefficient of less than 0.5 , it can be seen that the lowest RMSE and highest correlation coefficient were obtained when using the ERA5 wind data, which had a high overall accuracy. Also, the RMSE for the peak wave period simulation results appears to be similar to the wind speed and wind direction RMSEs in Fig. 4, and it is believed that the accuracy of the wind speed and wind direction prediction has a large effect on predicting the periodic components of waves. 

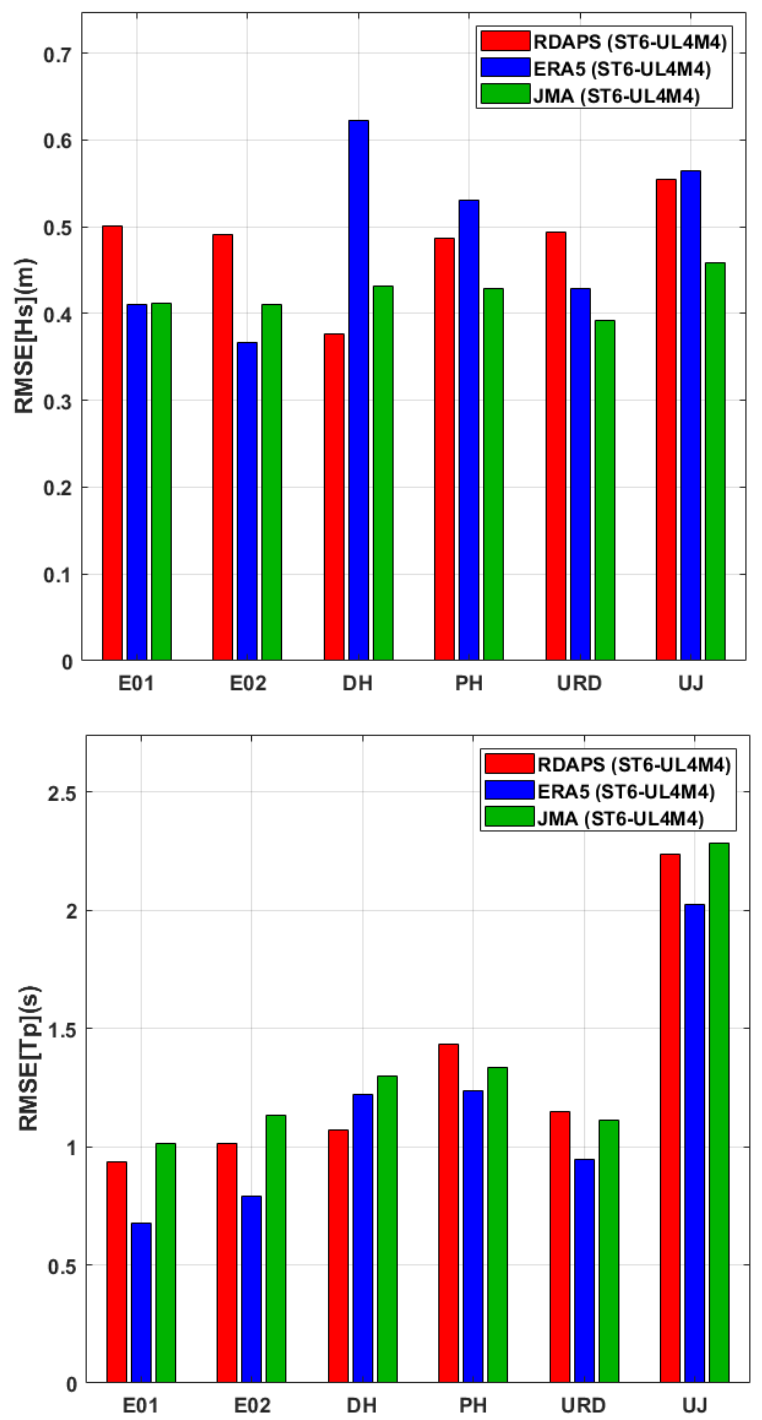

(a)
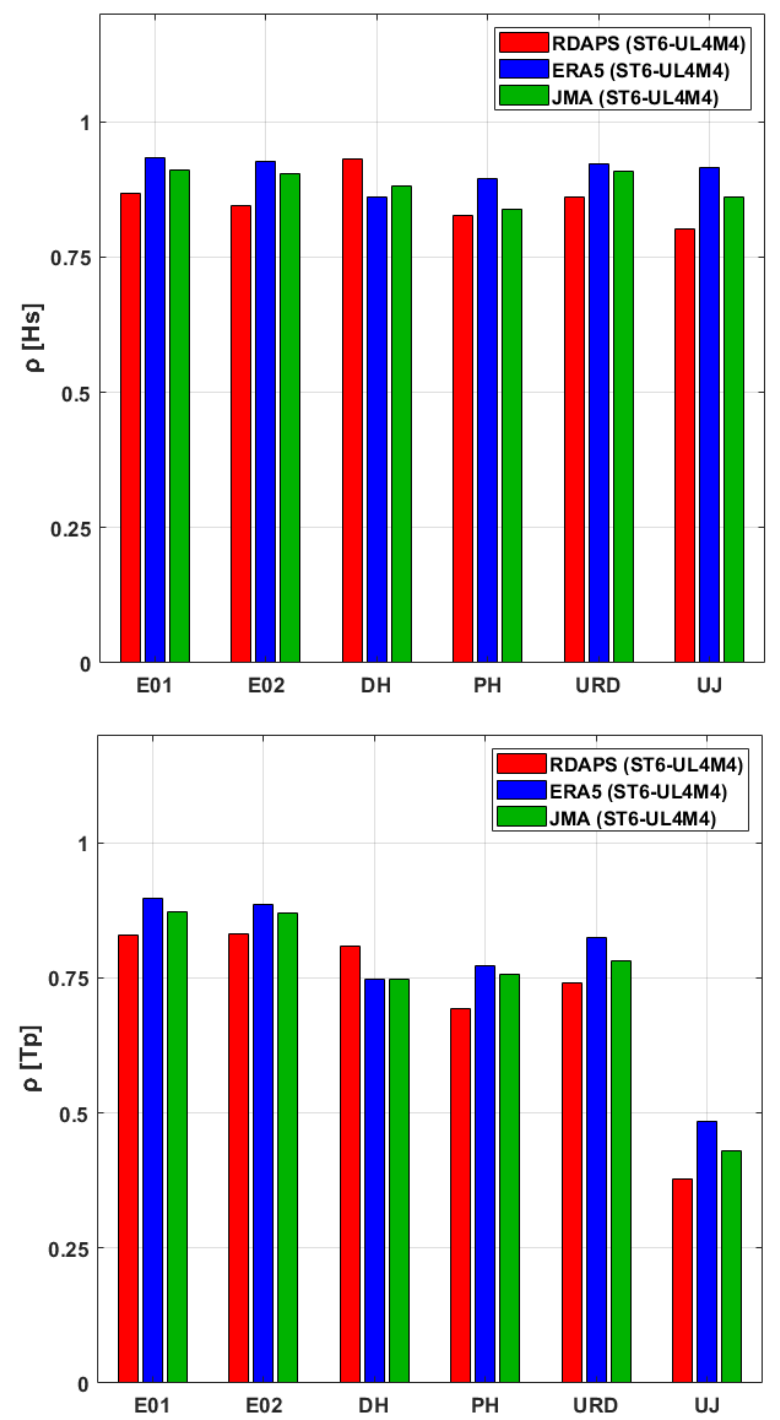

(b)

Fig. 9 Bar graphs of (a) RMSE and (b) correlation coefficient of wave simulation results for significant wave height (Hs) and peak wave period $(T p)$ during the simulation period (11.01.2016-02.28.2017)

\section{Conclusions}

This study used SWAN, a third-generation numerical wave model that is the most widely-used model in the field of coastal engineering, and ST6, which incorporates physical coefficients created based on observational research, to build and optimize a numerical wave model that can be applied to the East Sea during winter. To evaluate the reproducibility of the ST6, the numerical wave model was run using 4 different parameter combinations (DL1M1, UL1M4, UL2M2, and UL4M4) that were verified by Rogers et al. (2012) and spatialtemporal wind data (RDAPS, ERA5, and JMA-MSM) provided by various organizations as input, and the parameter settings with the best reproducibility were found. The results were compared to those obtained using the empirical equation by Komen et al. (1984), which is the default option in the SWAN model. In addition, a comparison was made between the simulation results obtained using the spatial- temporal wind data provided by each organization, and the reproducibility of the simulation results was evaluated according to the input wind data.

Looking at the ST6 models with the 4 different parameter settings, it was found that the significant wave height reproducibility was best when using the UL4M4 parameters, and it was possible to obtain higher reproducibility by adjusting the parameters compared to using the empirical equation by Komen et al. (1984). In the case of peak wave period, there was poor consistency in the results according to each model, observing locations, and evaluation item, and it was difficult to evaluate reproducibility. When looking at the simulation results obtained by using each organization's wind data, which had different characteristic, it was found that the best simulation results for significant wave height and peak wave period were obtained by using the ERA5 wind data. However, when predicting hazardous waves with great temporal variability, large wave heights were better simulated by 
RDAPS and JMA-MSM wind data, which are forecast models with worse wind speed accuracy but better spatial resolution than ERA5. This confirmed that the input wind data's spatial resolution quality has a greater effect on wave prediction than wind speed accuracy when predicting large-height waves great temporal variability.

Ultimately, it was confirmed that ST6 can simulate the waves that occur in the East Sea to a certain extent by using various parameter settings instead of the empirical equation by Komen et al. (1984) used in existing numerical wave models. Also, it is believed that wind data with excellent spatial resolution quality are required to predict hazardous waves, which are characterized by large heights and occurrence during severe weather. Therefore, it will be possible to build a numerical wave model that can be applied to the entire East Sea by using a nesting method on the coastal areas. However, this study was not able to properly simulate significant wave heights that rapidly increased by more than $4 \mathrm{~m}$ and which occurred on December 19-31, 2016, January 8-18, 2017, or around February 21, 2017. There was an error of approximately $1 \mathrm{~m}$ in the simulation results for the location URD around January 20 and at locations $\mathrm{DH}, \mathrm{PH}$, and UJ around January 30 . This means that third-generation numerical models, which calculate the wave energy spectrum using a wave action density equilibrium equation, are limited in predicting hazardous waves, such as storm waves and large-height swell-like waves that occur during typhoons and periods of severe weather. As such, it will be necessary to continue studying simulations for waves that occur in various environments, including severe weather conditions, and it will be necessary for data assimilation, which are used to increase prediction accuracy in the field of meteorology, to be applied to wave predictions to overcome the limitations of hazardous wave prediction.

\section{Funding}

This study was supported by a National Research Foundation of Korea grant funded by the Korea government (NRF-2019R1C1C 1003160), and by the project titled "Establishment of the Ocean Research Station in the Jurisdiction Zone and Convergence Research" funded by the Ministry of Oceans and Fisheries in Korea.

\section{References}

Booij, N., Ris, R.C., \& Holthuijsen, L.H. (1999). A Third-generation Wave Model for Coastal Regions: 1. Model Description and Validation. Journal of Geophysical Research: Oceans, 104(C4), 7649-7666. https://doi.org/10.1029/98JC02622

Caires, S., Kim, J., \& Groeneweg, J. (2018). Korean East Coast Wave Predictions by Means of Ensemble Kalman Filter Data Assimilation. Ocean Dynamics, 68, 1571-1592. https://doi.org/ 10.1007/s10236-018-1214-0

Chun, H., Kang, T.-S., Ahn, K., Jeong, W.M., Kim, T.-R., \& Lee, D.H. (2014). A Study on the Statistical Characteristics and Numerical Hindcasts of Storm Waves in East Sea. Journal of Korean Society of Coastal and Ocean Engineers, 26(2), 81-95. https://doi.org/ 10.9765/kscoe.2014.26.2.81

Do, K., \& Kim, J. (2018). A Study on the Predictability of Eastern Winter Storm Waves Using Operational Wind Forecasts of KMA. Journal of Korean Society of Coastal and Ocean Engineers, 30(5), 223-233. https://doi.org/10.9765/kscoe.2018. 30.5.223

Eum, H.-S., Kang, T.-S., Nam, S.-Y., \& Jeong, W.-M. (2016). Wave Modeling Considering Water Level Changes and Currents Effects. Journal of Korean Society of Coastal and Ocean Engineers, 28(6), 383-396. https://doi.org/10.9765/kscoe.2016. 28.6.383

Hasselmann, K., Barnett, T.P., Bouws, E., Carlson, H., Cartwright, D.E., Enke, K., ... Walden, H. (1973) Erganzungsheft zur Deutschen Hydrographischen Zeitschrift, Reihe A $\left(8^{\circ}\right)$, 12, Hambur: Deutsches Hydrographisches Institut.

Jeong, W.-M., Oh, S.-H., Ryu, K.-H., Back, J.-D., \& Choi, I.-H. (2018). Establishment of Wave Information Network of Korea (WINK). Journal of Korean Society of Coastal and Ocean Engineers, 30(6), 326-336. https://doi.org/10.9765/kscoe.2018. 30.6.326

Kang, T.-S., Park, J.-J., \& Eum, H.-S. (2015). Coastal Wave Hind-Casting Modelling Using ECMWF Wind Dataset. Journal of the Korean Society of Marine Environment and Safety, 21(5), 599-607. https://doi.org/10.7837/kosomes.2015.21.5.599

Kim, G.H., Ryu, K.H., \& Yoon, S.B. (2020). Numerical Simulation of Storm Surge and Wave due to Typhoon Bolaven of 2012. Journal of Korean Society of Coastal and Ocean Engineers, 32(4), 273283. https://doi.org/10.9765/kscoe.2020.32.4.273

Komen, G.J., Hasselmann, S., \& Hasselmann, K. (1984). On the Existence of a Fully Developed Wind-sea Spectrum. Journal of Physical Oceanography,14(8), 1271-1285. https://doi.org/10. 1175/1520-0485(1984)014<1271:OTEOAF >2.0.CO;2

Kwon, K.K., Jho, M.H., Ryu, K.H., \& Yoon, S.B. (2020). Analysis of Reliability of Weather Fields for Typhoon Sanba (1216). Journal of Korean Society of Coastal and Ocean Engineers, 32(6), 465480. https://doi.org/10.9765/kscoe.2020.32.6.465

Lee, B., \& Ahn, S. (2018). Improved Reproducibility of the Yellow and East China Sea Wave Model by Adjusting Parameter of SWAN. Journal of the Korean Society for Marine Environment \& Energy, 21(3), 207-215. https://doi.org/10.7846/jkosmee. 2018.21.3.207

Lee, C., Ahn, S. J., Lee, B. W., Kim, S. W., \& Kwon, S.J. ( 2014). Prediction of Swell-like High Waves Using Observed Data on the East Coast of Korea. Journal of Korean Society of Coastal and Ocean Engineers, 26(3), 149-159. https://doi.org/10.9765/kscoe. 2014.26.3.149

Lee, H.S., Kim, K.O., Yamashita, T., Komaguchi, T., \& Mishima, T. (2010). Abnormal Storm Waves in the Winter East/Japan Sea: Generation Process and Hindcasting Using an Atmosphere-wind Wave Modelling System. Natural Hazards and Earth System 
Science, 10(4), 773-792. https://doi.org/10.5194/nhess-10-7732010

Oh, S.-H., Jeong, W.M., Lee, D.Y., \& Kim, S.I. (2010). Analysis of the Reason for Occurrence of Large- Height Swell-like Waves in the East Coast of Korea Analysis of the Reason for Occurrence of Large-Height Swell-like Waves in the East Coast of Korea. Journal of Korean Society of Coastal and Ocean Engineers, 22(2), 101-111.

Park, K.S., Heo, K.Y., Jun, K., Kwon, J.I., Kim, J., Choi, J.Y., ... Jeong, S.H. ( 2015). Development of the Operational Oceanographic System of Korea. Ocean Science Journal, 50(2), 353-369. https://doi.org/10.1007/s12601-015-0033-1

Rogers, W.E., Babanin, A.V., \& Wang, D.W. (2012). Observationconsistent Input and Whitecapping Dissipation in a Model for Wind-generated Surface Waves: Description and Simple Calculations. Journal of Atmospheric and Oceanic Technology, 29(9), 1329-1346. https://doi.org/10.1175/JTECH-D-11-00092.1

Rogers, W.E., Hwang, P.A., \& Wang, D.W. (2003). Investigation of Wave Growth and Decay in the SWAN Model: Three regional-scale Applications. Journal of Physical Oceanography, 33(2), 366-389. https://doi.org/10.1175/1520-0485(2003)033< 0366:IOWGAD $>2.0 . \mathrm{CO} ; 2$

Saito, K., Fujita, T., Yamada, Y., Ishida, J.I., Kumagai, Y.,
Aranami, K., ... Yamazaki, Y. (2006). The Operational JMA Nonhydrostatic Mesoscale Model. Monthly Weather Review, 134(4), 1266-1298. https://doi.org/10.1175/MWR3120.1

WAVEWATCH III Development Group. (2016). User Manual and System Documentation of WAVEWATCH III Version 5.16 (Technical Note 329). USA: NOAA/NWS/NCEP/MMAB.

WAMDI Group. (1988). The WAM Model-A Third Generation Ocean Wave Prediction Model. Journal of Physical Oceanography, 18(12), 1775-1810. https://doi.org/10.1175/ 1520-0485(1988)018<1775:TWMTGO $>2.0 . C O ; 2$

Yoon, S.B., Jeong, W.M., Jho, M.H., \& Ryu, K.H. (2020). Analysis of Reliability of Weather Fields for Typhoon Maemi (0314). Journal of Korean Society of Coastal and Ocean Engineers, 32(5), 351-362. https://doi.org/10.9765/kscoe.2020.32.5.351

Zijlema, M., Van Vledder, G.P., \& Holthuijsen, L.H. (2012). Bottom Friction and Wind Drag for Wave Models. Coastal Engineering, 65, 19-26. https://doi.org/10.1016/j.coastaleng.2012.03.002

\section{Author ORCIDs}

Author name

Son, Bongkyo

Do, Kideok
ORCID

0000-0002-6328-7286 0000-0001-7364-8375 